\title{
The Application of Fuzzy Algorithm in Selecting Machining Process Dosage
}

\author{
Guo Peng ${ }^{1, a}$ \\ ${ }^{1}$ Shandong Polytechnic, Jinan, 250104, Shandong, China \\ a407103668@qq.com
}

Keywords: Process dosage, Fuzzy Mathematics, Optimized choice

\begin{abstract}
This paper describes the practical application of fuzzy mathematical algorithm in selecting the process dosage of machining with examples. The paper illustrates this method in detail from mathematical model to typical verified examples. Popularization and application of this method can provide a powerful assist in optimizing the choice of cutting parameters for modern manufacturing enterprises.
\end{abstract}

\section{Introduction}

In machining process, the optimization and selection of cutting parameters has become an extremely important economic issue of modern machinery manufacturing. Under the same processing conditions, the use of different cutting parameters will produce different cutting effects. Productivity, cost of production, processing accuracy, surface quality and other aspects all depend on the correct choice of cutting parameters. The main factors affecting the choice of cutting parameters are: cutting speed, quality grade, cutting power, tool life, surface roughness, and so on [1]. In fact, the influence degrees of various factors on the cutting parameters are fuzzy at the moment. Many factories set cutting parameters according to reference manual, practice information or experiences. As the cutting parameters recommended are obtained under certain experimental conditions, and used in a variability of the actual processing environment, that means there is a certain degree error, so the cutting parameter is an uncertain fuzzy quantity essentially. When cutting parameters need selecting accurately and reasonably, a series of analysis to each factor should be made, and quantitative evaluation should be made based on the influence degree of each factor on the cutting parameters selected by fuzzy mathematical theory [2].

\section{Establish the Mathematical Model of Fuzzy Comprehensive Evaluation}

The application of fuzzy mathematics method to evaluate object is affected by many factors during the process of fuzzy comprehensive evaluation. In order to achieve the purposes, it is necessary to optimize fuzzy concept of a variety of programs with multiple criteria. Generally it is made up of monopole fuzzy comprehensive evaluation and multipole fuzzy comprehensive evaluation [3].

\section{Establish the standby Selected Set}

The standby selected set is the set of parameters to be selected, expressed as:

$$
\mathrm{V}=(\mathrm{v} 1, \mathrm{v} 2, \mathrm{v} 3, \ldots, \mathrm{vj}) \mathrm{j}=1,2 \ldots \mathrm{m}
$$

\section{Establish the Factors Set}

Analyze object or thing to be judged, identify all the factors that affect them, establish the factors set:

$\mathrm{U}=(\mathrm{u} 1, \mathrm{u} 2, \mathrm{u} 3, \ldots, \mathrm{ui}) \mathrm{i}=1,2 \ldots, \mathrm{n}$

The above-mentioned factors are divided into several levels according to the influence trend of judgment object; each level is given a score:

ui $=(5,4,3,2,1,0) i=1,2 \ldots n$ 


\section{One-Level Fuzzy Comprehensive Evaluation}

By analyzing the various factors of affecting the evaluation object, the relationship between factors set and judgment set could be represented with fuzzy relation matrix (R(ri1,ri2,..,rij)n*m) by membership function.[4]

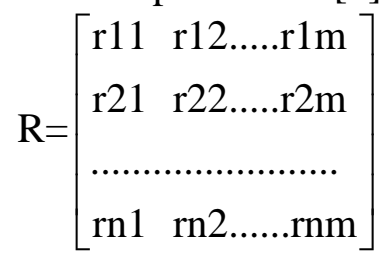

Among them, $0 \leqslant$ rij $\leqslant 1 \quad i=1,2 \cdots n, j=1,2 \cdots m$

By calculating membership degree with the i-th factor for the j-th program, the membership could be corresponded by the $\mathrm{j}$-th program constitutes evaluation matrix:

$\mathrm{R}(\mathrm{ri} 1, \mathrm{ri} 2, \ldots, \mathrm{rij}) \mathrm{n} * \mathrm{mi}=1,2 \ldots \mathrm{n}, \mathrm{j}=1,2 \ldots \mathrm{m}$

Secondary Fuzzy Comprehensive Evaluation

First, Establish Factor Weight Set

By analyzing the impact of various factors on the evaluation object, establish factor evaluation matrix:

$\mathrm{A}=(\mathrm{a} 1, \mathrm{a} 2, \ldots, \mathrm{ai}) \mathrm{i}=1,2, \ldots, \mathrm{n}$

The weight value determination method used in fuzzy mathematics includes arithmetic mean method and frequency statistic method [5].

Second, Comprehensive Evaluation

$B=A \quad R=(b 1, b 2, \ldots, b j) j=1,2, \ldots m$

Among them,

$\mathrm{bj}=\sum_{i=1}^{n} a i \times r i j \quad \mathrm{j}=1,2, \ldots \mathrm{m}$

Matrix (b1, b2, ..., bj) were normalized:

$B_{i j}=b_{i j} / \sum_{j=1}^{m} b_{i j}(i=1,2, \ldots \ldots n ; j=1,2, \ldots \ldots m)$

$\mathrm{B}(\mathrm{B} 1, \mathrm{~B} 2, \ldots, \mathrm{Bj})(\mathrm{j}=1,2, \ldots \mathrm{m})$

\section{Optimized the Programs}

According to maximum membership degree law, compared each element among $B(B 1, B 2, \ldots, B j)$, and steeled sort, large value element corresponding to the alternative is the best [6].

\section{Examples and application}

It is known that the workpiece material is low-alloy steel, while tool material is hard alloy steel (YT15). Turning cylindrical to $\Phi 30^{*} 150$ by lathe C512, the surface roughness of workpiece is $\mathrm{Ra}=3.2-1.6$. Determine the feed when the semi-finishing cut size is $2 \mathrm{~mm}$.

\section{Establish the Standby Selected Set}

According to the known conditions, the range of feed is from $0.3 \mathrm{~mm} / \mathrm{r}$ to $0.4 \mathrm{~mm} / \mathrm{r}$, the drawing pace is 0.025 .

$\mathrm{V}=(0.3,0.325,0.35,0.375,0.4)$

Establish the Factors Set

$\mathrm{U}=(u 1, u 2, u 3, \ldots, u i) \mathrm{i}=1,2 \ldots, n$

Among them, u1-speed of turning,

u2-quality grade,

u3 - cutting power,

u4-tool life,

u5-surface roughness.

First, Speed of Turning 
$\mathrm{v}=\frac{\mathrm{Cv}}{\mathrm{T}^{\mathrm{m}} \times \mathrm{a}_{\mathrm{p}}^{\mathrm{x}_{\mathrm{v}}} \times \mathrm{f}^{\mathrm{y}_{\mathrm{v}}}}(\mathrm{m} / \mathrm{min})$

Among them: $\mathrm{C}_{\mathrm{v}}, \mathrm{x}_{\mathrm{v}}, \mathrm{y}_{\mathrm{v}}, \mathrm{m}$ - cutting speed coefficient,

$\mathrm{T}$ - tool life,

$a_{p}$ - cutting depth.

Secord, Quality Grade

The workpiece is generally divided into six grades $1,2,3,4,5,6$, the workpiece can be achieved according to company or country specified quality level.

Third, Cutting Power

$\mathrm{F}_{\mathrm{z}}=\mathrm{C}_{\mathrm{F}_{z}} \times a_{p}^{x_{F_{v}}} \times f^{y_{F_{v}}} \times v^{n_{F_{z}}} \times k_{F_{z}} \mathrm{~N}$

$\mathrm{P}_{\mathrm{m}}=\frac{\mathrm{F}_{\mathrm{z}} \times \mathrm{V}}{6 \times 10^{4}} \mathrm{KW}$

Among them: $\mathrm{C}_{\mathrm{F}_{\mathrm{z}}}, \mathrm{x}_{\mathrm{F}_{\mathrm{z}}}, \mathrm{y}_{\mathrm{F}_{\mathrm{z}}}, \mathrm{n}_{\mathrm{F}_{\mathrm{z}}}$ - the coefficient of main cutting force $\left(\mathrm{F}_{\mathrm{z}}\right)$

$\mathrm{k}_{\mathrm{F}_{\mathrm{z}}}$-cutting force correction coefficient

Fourth, Tool Life

$T=\frac{C_{T}}{v^{z} \times f^{y} \times a_{p}^{x}}$

Among them: $C_{T}$-tool life coefficient

Fifth, Surface Roughness

$$
\mathrm{z}, \mathrm{x}, \mathrm{y} \text {-index }
$$

$R_{a}=\frac{f}{4 \times\left(\operatorname{ctg} K_{r}+\operatorname{ctg} K_{r}^{\prime}\right)}$

Among them: $K_{r}$ - cutting edge angle

$$
K_{r}^{\prime} \text {-assistant deflection angle }
$$

\section{One-Level Fuzzy Comprehensive Evaluation}

According to a function between various factors and evaluation of objects, calculate membership of the programs corresponded by each factor.

$$
\mathbf{R}=\left[\begin{array}{lllll}
0.062 & 0.173 & 0.290 & 0.413 & 0.544 \\
0.4 & 0.4 & 0.2 & 0.1 & 0.1 \\
0.107 & 0.151 & 0.194 & 0.236 & 0.277 \\
0.078 & 0.156 & 0.284 & 0.638 & 1.0 \\
0.803 & 0.732 & 0.655 & 0.572 & 0.484
\end{array}\right]
$$

\section{Secondary Fuzzy Comprehensive Evaluation}

First, Establish factor weight set

This example used the frequency statistics. Each expert given weight vector of factor set that affect the feed independently, then multiple weights of each factor were frequency statistics, the weight vector of factor set was:

$\mathrm{A}=(0.21,0.27,0.18,0.19,0.15)$

Second, Comprehensive Evaluation

$\mathrm{B}=\mathrm{A} \times \mathrm{R}=(0.275,0.311,0.302,0.363,0.454)$

The matrix was normalized: $(0.161,0.182,0.177,0.214,0.266)$ 


\section{Optimize the Programs}

According to the principle of maximum membership, select the secondary fuzzy comprehensive evaluation maximum 0.266 corresponding program, which is the fifth program, and the feed is $0.4 \mathrm{~mm} / \mathrm{r}$.

After determining the feed, the cutting speed is calculated according to the function formula between feed and cutting speed. Then according to the following formula, determine the lathe spindle speed.

$$
\mathrm{n}=\frac{1000 \times \mathrm{v}}{\mathrm{PI} \times \mathrm{d}} \mathrm{m} / \mathrm{min}
$$

Then, after rounding, calculate the actual feed and cutting speed of lathe itself.

\section{Summary}

Using fuzzy comprehensive evaluation method to precisely select some indeterminate amount, the uncertainty chosen by experiences only can be avoided. This article came from the practice, and aimed to discuss fuzzy mathematics method used in selecting machining process dosage, which includes the establishment of the mathematical model of fuzzy comprehensive evaluation, as well as the demonstration of typical examples. Although the paper only took the feed as an example for comprehensive evaluation, as a scientific evaluation method, the fuzzy comprehensive evaluation is also practical for other evaluation objects. If a variety of influencing factors and constraint condition under the processing can be fully considered, the results can be optimized quickly and accurately.

\section{References}

[1] Chen Hongjun: Practical mechanical process manual. (China Machine Press, China 2003).

[2] Li Hongji: Fuzzy Mathematical Foundation and Practical Algorithm. (Science Press, China 2005)

[3] Zhu Xiaolin and Xu Hanzhen: Adaptive Fuzzy Expert System for Collision Avoidance of Ships. Journal of Huazhong University of Science and Technology Vol. 38-39 (2002), p. 12

[4] Huo Runke and Li Ning: An Ex per t System for Prediction Fissure Rock Water in Neotectonic Movement Area Based on Fuzzy Neural Network. Systems Engineering-Theory \& Practice Vol. 22-24 (2003), p. 4

[5] Wang Na and Zhang Bofeng: Research on a Personalized ES Explanation in Expert System. Journal of Computer Applications Vol. 44-46 (2001), p. 5

[6] Wu Zhao and Yin Chaoqing: The design of reasoning machine in fuzzy expert system. Journal of Wuhan Institute of Chemical Technology Vol. 14-15 (2003), p. 6 